\title{
Gastrointestinal tract response and growth performance of growing turkeys as influenced by the whole wheat content of diets in two feeding programmes
}

\author{
J. Jankowski ${ }^{1,3}$, D. Mikulski' ${ }^{1}$ Z. Zdunczyk ${ }^{2}$, J. Juskiewicz² and K. Lichtorowicz ${ }^{1}$ \\ 1 University of Warmia and Mazury, Department of Poultry Science, Oczapowskiego 5, 10-718 Olsztyn, Poland \\ ${ }^{2}$ Institute of Animal Reproduction and Food Research, Polish Academy of Sciences, Tuwima 10, 10-747 Olsztyn, Poland
}

KEY WORDS: wheat, gastrointestinal tract function, growth performance, carcass traits, turkeys

Received: 5 December 2013

Revised: 27 August 2014

Accepted: 10 September 2014

${ }^{3}$ Corresponding author:

e-mail: janj@uwm.edu.pl

\begin{abstract}
The objective of this study was to determine the physiological responses and growth performance of turkeys fed $20 \%$ whole wheat (WW) in two feeding programmes, diets A and B, consistent with the NRC (1994) and B.U.T. (2012) recommendations, respectively. In diet $B$, in successive feeding periods (weeks 5-18), the soyabean meal content was increased by $2.89 \%$ to $5.13 \%$, the wheat content was decreased by $5.29 \%$ to $8.18 \%$, and the concentrations of L-lysine, DL-methionine and L-threonine were considerably increased. A total of 896 four-week-old Big-6 male turkeys with similar initial body weights were randomly assigned to four equal dietary treatment groups, with seven replicate pens per treatment. The birds had free access to water and pelleted diets that contained no WW or 20\% WW. After 14 weeks of feeding, the body weight gains (BWG) of turkeys were similar in all dietary treatments. From week 13 to 18, WW contributed to a significant $(P=0.040)$ increase in the feed conversion ratio $(F C R)$, whereas the increase in FCR noted over the entire experiment was nearly significant $(P=0.065)$. Dietary inclusion of WW had no effect on the weights of the gizzard, small intestine, or caecum, and it enhanced fermentation in the caecum, including increasing a-glucosidase activity and the concentrations of total short-chain fatty acids, and decreasing the $\mathrm{pH}$ of caecal digesta (all $P=0.001$ ). No significant differences were noted in the parameters of gastrointestinal function and BWG between turkeys fed diets $A$ and $B$. Diet $B$ did, however, significantly $(P=0.045)$ improve FCR over the entire experiment.
\end{abstract}

\section{Introduction}

Whole grain cereals, primarily wheat (WW), are fed to poultry to reduce the growth of pathogenic bacteria through better crop and gizzard development, which enhances intestinal morphology and function, thus improving the growth rate and feed conversion of birds (Biggs and Parsons, 2009; Svihus et al., 2010; Amerah et al., 2011). Feeding whole grains to poultry also increases economic efficiency by reducing the costs of production and transport of compound feeds (Svihus, 2010; Bennett et al., 2002). Another advantage of more natural' feeding systems is greater consumer acceptance (Gabriel et al., 2008).

In experiments on chickens, whole grains were included at 10\%-20\% (Amerah and Ravindran, 2008 ), or even $20 \%-40 \%$ of the daily diet (Gabriel 
et al., 2008). An experiment on turkeys has demonstrated that turkeys can be successfully fed a diet containing $50 \%$ whole wheat or barley (Bennett et al., 2002). Dilution of a complete turkey diet with $30 \% \mathrm{WW}$ reduced the final body weight and the weight of breast meat per bird by $15 \%$ and $20 \%$, respectively (Bennett and Classen, 2003).

Our previous study (Jankowski et al., 2012a) showed that moderate dilution of complete turkey diets with wheat $(18 \%$ on average from weeks 4 to 18) had no effect on the final body weights of birds or muscle yield, and improved feed efficiency. It was also found that supplementation of turkey diets with WW improved feed conversion as a result of better GIT function, lower $\mathrm{pH}$ of gizzard digesta, increased crypt depth in the jejunum, lower ammonia concentrations, lower $\mathrm{pH}$ in intestinal digesta, a higher proportion of Eubacteria and Bifidobacterium sp. and lower Salmonella sp. counts in intestinal microflora, and increased concentrations of butyric acid and total short-chain fatty acids (SCFAs) in the caecal digesta (Zdunczyk et al., 2013).

The results of another study, in which whole grain wheat was supplemented with appropriate protein, fat and mineral concentrate (Jankowski et al., 2013), showed that the lowest WW content of diets (up to $15 \%$ of the daily ration from week 4 to 12 ) had no effect on the growth performance and gastrointestinal function parameters of turkeys, while two-fold higher WW inclusion levels significantly increased gizzard weight, deteriorated feed conversion ratio (FCR), but did not decrease the body weight gain (BWG) of birds. A further increase in the inclusion rates of WW in turkey diets, in particular complete substitution of WW for ground and pelleted wheat, considerably affected the physicochemical and microbiological parameters of intestinal digesta, including an increase in Escherichia coli counts, and also significantly decreased the BWG of birds and deteriorated FCR.

According to Blair and Potter (1989) and Ferket and Sell (1990), the total protein content of turkey diets can be reduced even by $20 \%$ (relative to the NCR, 1994, recommendations) with no negative effect on the growth rate of birds, provided that the energy density of the diet is adequate. Further studies are needed to determine whether the above findings can be extrapolated to modern strains of heavy-type turkeys. It remains unknown if those birds respond to relatively small differences in protein content resulting from WW inclusion in the diet or different feeding strategies.
The aim of this study was to determine the physiological responses and growth performance of turkeys fed pelleted diets with different physical forms of wheat, i.e. exclusively ground wheat or $20 \%$ wheat as whole grain. The effects of the diet with WW were compared in two feeding programmes (diets A and B) consistent with NRC (1994) or B.U.T. (2012) recommendations.

\section{Material and methods}

\section{Birds and housing}

A total of 896 four-week-old heavy-type Big-6 male turkeys (Hatchery Grelavi Co., Kętrzyn, Poland) were randomly assigned to four dietary treatments, with seven replicate pens per treatment and 32 birds per pen. The birds had free access to pelleted diets and water. All diets were fed throughout four experimental periods, i.e. weeks $5-8,9-12,13-16$ and $17-18$.

The experiment was carried out at the Research Laboratory of the Department of Poultry Science, University of Warmia and Mazury, Olsztyn (Poland). The protocol for this study was approved by the Local Ethics Committee, and the study was carried out in accordance with EU Directive 2010/63/EU for animal experiments.

\section{Experimental design and diets}

A $2 \times 2$ factorial arrangement of four dietary treatments was used to evaluate the effects of isoenergetic diets that contained no WW or $20 \% \mathrm{WW}$ on the growth performance, carcass traits and gastrointestinal tract response of growing turkeys (5-18 wk). Diets diluted with different physical forms of wheat were administered in two feeding programmes: $\operatorname{diet} \mathrm{A}$, consistent with the NRC recommendations (1994) and diet B, consistent with the B.U.T. recommendations (2012). The diameters of pellets in diets with and without WW, administered during weeks 5-8 and 9-18, were $3 \mathrm{~mm}$ and $4 \mathrm{~mm}$, respectively.

Wheat grain from the same batch was used in all dietary treatments, and its chemical composition was estimated based on crude protein content $(12 \%)$ and Polish Feedstuff Analysis Tables (Smulikowska and Rutkowski, 2005). The nutritional value of wheat grain used in the study (Table 1) was used to calculate the nutrient composition of experimental diets. WW accounted for $20 \%$ of the ration, irrespective of the total wheat content. A preliminary trial showed that the maximum inclusion rate of WW in turkey diets is $20 \%$, as it has no adverse effects on the pelletizing process and pellet cohesion. 
Table 1. Dietary ingredients and the nutrient content $\left(\mathrm{g} \cdot \mathrm{kg}^{-1}\right.$ as-fed basis) of diets fed to turkeys from 5 to 18 weeks of age

\begin{tabular}{|c|c|c|c|c|c|c|c|c|}
\hline \multirow{2}{*}{ Indices } & \multicolumn{2}{|c|}{$5-8 w k$} & \multicolumn{2}{|l|}{$9-12 w k$} & \multicolumn{2}{|c|}{$13-16$ wk } & \multicolumn{2}{|c|}{$17-18 w k$} \\
\hline & $A^{1}(N R C)$ & $B^{1}(B \cup T)$ & $\overline{A(N R C)}$ & $B(B \cup T)$ & $A(N R C)$ & $B(B \cup T)$ & $\overline{A(N R C)}$ & $B(B \cup T)$ \\
\hline \multicolumn{9}{|l|}{ Ingredients } \\
\hline ground wheat & 438.5 & 385.6 & 556.0 & 474.2 & 642.2 & 570.5 & 706.4 & 627.1 \\
\hline soyabean meal (46\% CP) & 396.1 & 425.0 & 265.0 & 316.3 & 177.9 & 220.5 & 104.3 & 149.1 \\
\hline sunflower meal & 30 & 30 & 40 & 40 & 40 & 40 & 40 & 40 \\
\hline rape seed $(20.7 \%$ CP) & 60 & 60 & 70 & 70 & 70 & 70 & 80 & 80 \\
\hline soyabean oil & 27.2 & 36.5 & 15.5 & 29.3 & 19.9 & 32.5 & 14.4 & 28.3 \\
\hline lard & 10 & 10 & 20 & 20 & 20 & 20 & 30 & 30 \\
\hline limestone & 13.6 & 15.9 & 12.1 & 15.2 & 10.9 & 14.1 & 10 & 13.9 \\
\hline monocalcium phosphate & 14.1 & 23.4 & 10.6 & 21.7 & 8.9 & 19.9 & 6.2 & 19.2 \\
\hline choline chloride & 1 & 1 & 1 & 1 & 1 & 1 & 1 & 1 \\
\hline $\mathrm{Na}_{2} \mathrm{SO}_{4}$ & 1 & 1 & 1 & 1 & 1 & 1 & 1 & 1 \\
\hline $\mathrm{NaCl}^{2}$ & 2.2 & 2.2 & 1.8 & 1.8 & 1.8 & 1.8 & 1.9 & 1.9 \\
\hline DL-Methionine (99) & 1.3 & 3.1 & 0.7 & 2.7 & 0.6 & 2.5 & - & 2.3 \\
\hline L-Lysine HCL(78) & 2.3 & 3.1 & 3.4 & 3.1 & 2.2 & 3.1 & 1.8 & 3.3 \\
\hline L-Threonine (98.5) & 0.2 & 0.7 & 0.4 & 1.2 & 1.1 & 0.6 & 0.5 & 0.4 \\
\hline vitamin-mineral premix² & 2.5 & 2.5 & 2.5 & 2.5 & 2.5 & 2.5 & 2.5 & 2.5 \\
\hline \multicolumn{9}{|l|}{ Calculated analysis ${ }^{3}$} \\
\hline metabolizable energy, $\mathrm{kcal} \cdot \mathrm{kg}^{-1}$ & 2900 & 2900 & 3000 & 3000 & 3100 & 3100 & 3200 & 3200 \\
\hline crude protein & 260 & 268.5 & 220 & 235 & 190 & 201.9 & 165 & 177.8 \\
\hline lysine & 15.0 & 16.2 & 13.0 & 13.8 & 10.0 & 11.6 & 8.0 & 10.1 \\
\hline methionine & 5.0 & 6.9 & 4.0 & 6.1 & 3.5 & 5.5 & 2.7 & 5.0 \\
\hline methionine + cysteine & 9.5 & 11.4 & 8.0 & 10.3 & 7.1 & 9.3 & 6.0 & 8.5 \\
\hline threonine & 9.5 & 10.3 & 8.0 & 9.4 & 7.5 & 7.5 & 6.0 & 6.4 \\
\hline tryptophan & 3.4 & 3.5 & 2.8 & 3.0 & 2.4 & 2.6 & 2.1 & 2.2 \\
\hline arginine & 16.9 & 17.5 & 13.8 & 15.0 & 11.6 & 12.5 & 9.7 & 10.7 \\
\hline $\mathrm{Ca}$ & 10.0 & 12.6 & 8.5 & 11.8 & 7.5 & 10.8 & 6.5 & 10.4 \\
\hline available $P$ & 5.0 & 7.0 & 4.2 & 6.6 & 3.8 & 6.2 & 3.2 & 6.0 \\
\hline
\end{tabular}

${ }^{1}$ diets $A$ and $B$ consistent with the NRC (1994) and B.U.T. (2012) recommendations, respectively. In the diets $A_{w w}$ and $B_{w w} 200 \mathrm{~g}$ ground wheat was substituted by whole wheat; ${ }^{2}$ provided the following per kilogram of diet in the successive (5-12 and 13-18 weeks) feeding periods, mg: retinol 3.38 and 2.88, cholecalciferol 0.12 and 0.10, $\alpha$-tocopheryl acetate 94 and 80 , vit. $K_{3} 5.6$ and 4.8, thiamine 4.7 and 4.0, riboflavin 7.5 and 6.4, pyridoxine 5.6 and 4.8, cobalamin 0.028 and 0.024 , biotin 0.28 and 0.24 , pantothenic acid 24 and 20 , nicotinic acid 75 and 64 , folic acid 2.8 and 2.4, Fe 56 and 48, Mn 112 and 96, Zn 103 and 88, Cu 19 and 16, I 2.8 and 2.4, Se 0.28 and 0.24, choline chloride 376 and 320, respectively; ${ }^{3}$ calculated from the analysis of feed ingredients provided by the manufacturer

\section{Growth trial}

Before the experiment, from 1 to 4 weeks of age, all turkeys were fed identical commercial diets formulated to meet their nutrient requirements. Next, birds with similar initial body weights were assigned to four equal dietary treatment groups. A four-phase feeding programme (week 5-8, 9-12, $13-16$ and 17-18) was used during the study. At 8 , 12 and $18 \mathrm{wk}$, the turkeys were weighed and feed intake was recorded. The body weight gain of birds and feed conversion ratio were calculated for each feeding period. Mortality rates were recorded daily, and the body weights of dead birds were used to adjust for average daily gain, average daily feed intake, and FCR. At 56 and 126 days of age, fresh excreta samples from four birds per replicate pen were collected and pooled to determine excreta dry matter (DM) content. The experiment lasted for 126 days.
At the termination of the experiment, footpad dermatitis (FPD) scores for all birds were determined according to the method described by KrautwaldJunghanns et al. (2011), on a five-point scale (0-4 points) where 0 - the skin of the footpad feels soft to the touch and no swelling or necrosis is evident, 4 - more than half of the footpad is covered by necrotic cells. With regard to performance parameters, each replicate pen $(n=7)$ was considered an experimental unit for the statistical analysis.

\section{Carcass traits}

At 18 weeks of age, six birds representing the average weight of each treatment were selected and slaughtered in the Department's processing plant eight hours after feed withdrawal. The birds were electrically stunned $(400 \mathrm{~mA} ; 350 \mathrm{~Hz})$, hung on a shackle line and exsanguinated by a unilateral 
neck cut severing the right carotid artery and jugular vein. After a three-minute bleeding period, the birds were scalded at $61^{\circ} \mathrm{C}$ for $60 \mathrm{~s}$, defeathered in a rotary drum picker for $25 \mathrm{~s}$, and manually eviscerated (non-edible viscera: intestines, proventriculus, gall bladder, spleen, oesophagus and full crop). Head, neck, legs, edible viscera (heart, liver and gizzard), and fat (perivisceral, perineal and abdominal) were removed. Following evisceration, whole carcasses were air pre-chilled at $12^{\circ} \mathrm{C}$ for $30 \mathrm{~min}$, air chilled and stored at $4{ }^{\circ} \mathrm{C}$, and hand-deboned on a cone $24 \mathrm{~h}$ post mortem. The carcass, abdominal fat, breast meat (including pectoralis major and pectoralis minor muscles), and leg meat (including thigh and drumstick) were weighed. The percentage of eviscerated carcass was calculated as the ratio between the eviscerated carcass and live body weight after fasting. The weights of the liver, gizzard, breast meat, leg meat and abdominal fat were also calculated relative to live body weight.

\section{Sample collection}

Segments of the digestive tract (small intestine, caecum, colon) were removed. Digesta samples were collected, caeca were flushed with water, blotted on filter paper and weighed. The ileum was defined as the segment from Meckel's diverticulum to the ileo-caecal junction. As soon as possible after euthanasia (about $20 \mathrm{~min}$ ), $\mathrm{pH}$ was measured in digesta from each segment using a microelectrode and a pH-ion meter (model 301, Hanna Instruments, Vila do Conde, Portugal). Fresh samples of the ileal (middle 1/3 section of ileum) and caecal contents were used for the analysis of DM, ammonia, and short-chain fatty acids. The remaining portion of the caecal digesta was transferred to test tubes and stored at $-70^{\circ} \mathrm{C}$ until needed.

\section{Chemical analysis}

The DM content of excreta and caecal digesta was determined at $105^{\circ} \mathrm{C}$. Ammonia was determined by microdiffusion analysis in Conway's dishes (Hofirek and Haas, 2001) and SCFAs were analysed using a gas chromatograph (Shimadzu GC-2010, Kyoto, Japan) equipped with a capillary column (SGE BP21, $30 \mathrm{~m} \times 0.53 \mathrm{~mm}$, SGE Europe Ltd., Kiln Farm Milton Keynes, UK) as described earlier (Juskiewicz et al., 2011). The activity of bacterial enzymes ( $\alpha$ - and $\beta$-glucosidase, $\alpha$ - and $\beta$-galactosidase, $\beta$-glucuronidase, $\alpha$-arabinopyranosidase, $\beta$-xylosidase) released into the caecal environment was measured by the rate of $p$ - or $o$-nitrophenol release from their nitrophe- nylglucosides. The reaction mixture contained $0.3 \mathrm{ml}$ of a substrate solution $(5 \mathrm{mM})$ and $0.2 \mathrm{ml}$ of a 1:10 (v/v) dilution of the caecal sample in $100 \mathrm{mM}$ phosphate buffer (pH 7.0) after centrifugation at $7211 \mathrm{~g}$ for $15 \mathrm{~min}$. Incubation was carried out at $39^{\circ} \mathrm{C}$ and $r$-nitrophenol was quantified at 400 $\mathrm{nm}$ and at $420 \mathrm{~nm}$ (o-nitrophenol concentration) after the addition of $2.5 \mathrm{ml}$ of $0.25 \mathrm{M}$-cold sodium carbonate. The enzymatic activity was expressed as $\mu$ mol product formed per hour per gram of digesta. The above procedure concerns the extracellular activities of bacterial enzymes released from bacterial cells into the gastrointestinal environment (Juskiewicz et al., 2011). To determine the total enzymatic activity of selected bacterial enzymes in the caecal sample, which includes extracellular and intracellular activities of bacterial enzymes, the caecal sample diluted in phosphate buffer (as described above) was mechanically disrupted by vortexing with glass beads (212-300 $\mu \mathrm{m}$ diameter; four periods of $1 \mathrm{~min}$ with intervals of $1 \mathrm{~min}$ on ice). After that the resulting mixture was centrifuged at $7211 \mathrm{~g}$ for $15 \mathrm{~min}$ at $4{ }^{\circ} \mathrm{C}$. The supernatant was used for the enzyme assay. By comparison of the entire enzyme activity with the activity of bacterial enzyme released into the environment, the intracellular activity was calculated, and also expressed as $\mu \mathrm{mol}$ product ( $p$ - or $o$-nitrophenol) formed per hour per gram of digesta.

\section{Statistical analysis}

For growth performance analysis scores, seven pens per treatment and 32 birds per pen were used and each pen was considered an experimental unit. Other results were analysed with each bird as a replicate $(n=6)$. The model assumptions of normality and homogeneity of variance were examined by the Shapiro-Wilk and Levene tests, respectively. The statistical analysis was performed according to the GLM procedure for Statistica 10.0 software. The data were subjected to two-way ANOVA, to examine: a. the main effect of wheat grain $(0$ and $200 \mathrm{~g} \cdot \mathrm{kg}^{-1}$ ), b. the main effect of diet (diets A and $\mathrm{B}$ ), and $\mathrm{c}$. the interaction between the diet and wheat content. Growth performance data were performed by two-way ANOVA with initial body weight as the dependent variable (covariate). When the ANOVA indicated significant treatment effects, means were separated using the NewmanKeuls test (Snedecor and Cochran, 1989). The effects were considered to be significant at $P \leq 0.05$, and were expressed as mean values with pooled standard errors. 


\section{Results}

The present experiment aimed to determine the effects of two factors: the physical form of wheat in pelleted diets $(100 \%$ ground wheat and $80 \%$ ground wheat $+20 \% \mathrm{WW}$ ) and feeding programmes consistent with the NRC (1994) or B.U.T. (2012) recommendations on the physiological responses and growth performance of turkeys. The difference in protein content between $\operatorname{diet} \mathrm{A}$ and $\operatorname{diet} \mathrm{B}$ was initially small $(0.85 \%$ at $5-8 \mathrm{wk})$, and in successive feeding periods it increased to $1.5 \%, 1.19 \%$ and $1.28 \%$, respectively (Table 1). In diet $\mathrm{B}$, higher levels of protein and amino acids were achieved by increasing the concentrations of L-lysine, DL-methionine and L-threonine, and soyabean meal content (by $2.89 \%$ to $5.1 \%$ ), and decreasing wheat content by $5.29 \%-8.18 \%$ in successive feeding periods.

The applied dietary treatments had no effect on feed intake, BWG in successive feeding periods, or the final body weights of turkeys (Table 2). In the second and third phase (weeks 9-12 and 13-18), dietary inclusion of WW at $20 \%$ progressively deteriorated FCR ( $P=0.064$ and 0.040 , respectively), compared with ground wheat. The increase in FCR noted over the entire experiment was nearly significant $(P=0.065)$. No differences were found in BWG in successive feeding periods or in the final body weights of turkeys fed diets A and B. However, diet B significantly $(P=0.045)$ improved FCR over the entire experiment. The interaction between the experimental factors (wheat form $\times$ feeding programme) had no significant effect on BWG and FCR.

Carcass dressing percentage, relative size of valuable cuts (breast, thigh and drumstick muscles) as a percentage of liveweight, and carcass fat content were not significantly affected by diet composition (Table 3).

Gizzard weight was similar in all groups regardless of dietary treatment. Among the analysed pa-

Table 2. Growth performance and feed conversion ratio of turkeys from 5 to 18 weeks of age ${ }^{1}$

\begin{tabular}{|c|c|c|c|c|c|c|c|c|c|c|c|c|c|}
\hline \multirow[t]{2}{*}{ Effect } & \multicolumn{4}{|c|}{ DFI, g per bird } & \multicolumn{4}{|c|}{ BWG, kg } & \multirow{2}{*}{$\begin{array}{l}\text { Final } \\
\text { BW, kg }\end{array}$} & \multicolumn{4}{|c|}{ FCR, $\mathrm{kg} \cdot \mathrm{kg}^{-1}$} \\
\hline & $5-8$ wk & $9-12 w k$ & 13-18 wk & $5-18 w k$ & $5-8$ wk & $9-12$ wk & $13-18$ wk & $5-18 w k$ & & $5-8 w k$ & $9-12$ wk & $13-18$ wk & $5-18 w k$ \\
\hline \multicolumn{14}{|c|}{$e_{2}$} \\
\hline A & 231.6 & 448.5 & 605.2 & 447.1 & 3.77 & 5.60 & 8.69 & 18.06 & 19.40 & 1.79 & 2.25 & 2.96 & 2.49 \\
\hline$A_{\text {w }}$ & 233.9 & 460.6 & 601.7 & 450.6 & 3.86 & 5.49 & 8.52 & 17.87 & 19,21 & 1.78 & 2.32 & 3.02 & 2.53 \\
\hline$B^{w w}$ & 225.9 & 450.4 & 590.4 & 440.9 & 3.78 & 5.64 & 8.68 & 18.10 & 19.44 & 1.76 & 2.20 & 2.88 & 2.44 \\
\hline $\mathrm{B}_{w w}$ & 228.4 & 450.6 & 594.2 & 441.3 & 3.78 & 5.55 & 8.42 & 17.75 & 19.09 & 1.76 & 2.24 & 3.00 & 2.49 \\
\hline Pooled SEM & 1.366 & 2.674 & 5.992 & 2.926 & 0.026 & 0.034 & 0.087 & 0.107 & 0.108 & 0.008 & 0.015 & 0.023 & 0.012 \\
\hline \multicolumn{14}{|l|}{ Whole wheat } \\
\hline$W_{0}$ & 228.5 & 449.5 & 597.3 & 443.8 & 3.77 & 5.62 & 8.68 & 18.08 & 19.42 & 1.77 & 2.22 & $2.92^{b}$ & 2.46 \\
\hline$W_{200}$ & 231.2 & 455.6 & 597.9 & 446.0 & 3.82 & 5.52 & 8.47 & 17.81 & 19.15 & 1.77 & 2.28 & $3.01^{a}$ & 2.51 \\
\hline \multicolumn{14}{|l|}{ Diet 200} \\
\hline $\mathrm{A}(\mathrm{NRC})$ & $232.8^{a}$ & 455.0 & 603.3 & 449.0 & 3.81 & 5.54 & 8.60 & 17.96 & 19.29 & 1.78 & $2.29^{a}$ & 3.00 & $2.51^{a}$ \\
\hline B (B.U.T.) & $227.2^{b}$ & 450.5 & 592.3 & 441.1 & 3.78 & 5.59 & 8.55 & 17.93 & 19.27 & 1.76 & $2.22^{b}$ & 2.94 & $2.46^{b}$ \\
\hline \multicolumn{14}{|l|}{$P$} \\
\hline wheat (W) & 0.369 & 0.256 & 0.993 & 0.751 & 0.401 & 0.154 & 0.239 & 0.235 & 0.236 & 0.677 & 0.064 & 0.040 & 0.065 \\
\hline $\operatorname{diet}(\mathrm{D}$ & 0.045 & 0.455 & 0.381 & 0.211 & 0.581 & 0.496 & 0.762 & 0.869 & 0.871 & 0.159 & 0.024 & 0.221 & 0.045 \\
\hline$W \times D$ interaction & 0.965 & 0.277 & 0.776 & 0.806 & 0.385 & 0.903 & 0.814 & 0.720 & 0.723 & 0.846 & 0.596 & 0.479 & 0.859 \\
\hline
\end{tabular}

${ }^{1}$ data represent mean values of 7 replications per treatment. DFI - daily feed intake, BWG - body weight gain, FCR - feed conversion ratio, SEM - standard error of the mean (SD divided by the square root of the number of replications, $n=28$ ); ${ }^{2}$ diets $A$ and $B$ consistent with the NRC (1994) and B.U.T. (2012) recommendations, respectively. In the diets $A_{w w}$ and $B_{w w} 200 \mathrm{~g}$ ground wheat was substituted by whole wheat; ${ }^{a, b}$ means with different superscripts within columns for each main effect are significantly different at $P<0.05$. All interactions are insignificant

Table 3. Main effects of dietary treatments on slaughter yields of meat portions and tissues of turkeys (body weight $=100 \%$ ) at 18 weeks of age ${ }^{1}$

\begin{tabular}{lllllll}
\hline Effect & Carcass dressing & Breast & Thigh & Drumstick & Liver & Abdominal fat \\
\hline Whole wheat & & & & & & \\
$\quad$ WW & 83.40 & 23.55 & 10.82 & 7.89 & 0.86 & 1.25 \\
$\quad$ WW $_{200}$ & 83.65 & 24.05 & 11.02 & 7.80 & 0.83 & 1.21 \\
Diet & & & & & \\
A (NRC) & 83.76 & 23.88 & 10.88 & 7.95 & 0.86 & 1.24 \\
B (BUT) & 83.29 & 23.71 & 10.96 & 7.75 & 0.83 & 1.22 \\
Pooled SEM & 0.178 & 0.258 & 0.109 & 0.090 & 0.020 & 0.081 \\
$P \quad$ wheat (W) & 0.498 & 0.363 & 0.413 & 0.628 & 0.514 & 0.789 \\
diet (D) & 0.206 & 0.763 & 0.749 & 0.287 & 0.432 & 0.902 \\
W $\times$ D & 0.798 & 0.861 & 0.746 & 0.418 & 0.847 & 0.592 \\
\hline
\end{tabular}

${ }^{1}$ data represent mean values of 6 replications per treatment. SEM - standard error of the mean (SD divided by the square root of the number of replications, $n=24)$. All differences and interactions insignificant 
Table 4. Indices of intestinal development and function in turkeys ${ }^{1}$

\begin{tabular}{|c|c|c|c|c|c|c|c|}
\hline \multirow[b]{2}{*}{ Effect } & \multirow{2}{*}{$\begin{array}{l}\text { Gizzard, } \mathrm{g} \cdot \mathrm{kg}^{-1} \\
\text { BW }\end{array}$} & \multirow{2}{*}{$\begin{array}{l}\text { Small intestine } \\
\text { weight }^{2}\end{array}$} & \multirow[b]{2}{*}{$\begin{array}{l}\text { Caecal tissue } \\
\mathrm{g} \cdot \mathrm{kg} \mathrm{BW}\end{array}$} & \multicolumn{4}{|c|}{ Caecal digesta } \\
\hline & & & & $\mathrm{g} \cdot \mathrm{kg}^{-1} \mathrm{BW}$ & DM, \% & $\begin{array}{l}\text { ammonia, } \\
\mathrm{mg} \cdot \mathrm{g}^{-1}\end{array}$ & $\mathrm{pH}$ \\
\hline \multicolumn{8}{|l|}{ Treatment $^{3}$} \\
\hline A & 5.1 & 11.6 & 1.93 & 0.917 & 19.4 & 0.788 & 6.37 \\
\hline$A_{w w}$ & 5.5 & 12.3 & 1.90 & 0.888 & 19.1 & 0.754 & 5.85 \\
\hline$B^{w w}$ & 5.3 & 11.4 & 2.06 & 0.942 & 19.0 & 0.824 & 6.45 \\
\hline $\mathrm{B}_{w w}$ & 5.3 & 11.7 & 2.10 & 0.971 & 19.2 & 0.790 & 5.78 \\
\hline Pooled SEM & 0.012 & 0.316 & 0.046 & 0.050 & 0.320 & 0.033 & 0.084 \\
\hline \multicolumn{8}{|l|}{ Whole wheat } \\
\hline$W_{0}$ & 5.2 & 11.5 & 1.99 & 0.929 & 19.2 & 0.806 & $6.41^{\mathrm{A}}$ \\
\hline$W_{200}$ & 5.4 & 12.0 & 2.00 & 0.929 & 19.1 & 0.772 & $5.82^{\mathrm{B}}$ \\
\hline \multicolumn{8}{|l|}{ Diet } \\
\hline $\mathrm{A}(\mathrm{NRC})$ & 5.3 & 12.0 & 1.91 & 0.902 & 19.3 & 0.771 & 6.11 \\
\hline $\mathrm{B}(\mathrm{BUT})$ & 5.3 & 11.5 & 2.08 & 0.957 & 19.3 & 0.807 & 6.12 \\
\hline
\end{tabular}

${ }^{1}$ data represent mean values of 6 replications per treatment. SEM - standard error of the mean (SD divided by the square root of the number of replications, $n=24$ ). All interactions insignificant; ${ }^{2}$ total weight with contents, $g \cdot \mathrm{kg}^{-1} \mathrm{BW} ;{ }^{3}$ diets $A$ and $B$ consistent with the NRC (1994) and B.U.T. (2012) recommendations, respectively. In the diets $A_{w w}$ and $B_{w w} 200 \mathrm{~g}$ ground wheat was substituted by whole wheat; ${ }^{A} B$ means with different superscripts within columns for each main effect are significantly different at $P<0.01$

Table 5. Extracellular and intracellular activity of bacterial enzymes in the caeca of turkeys ${ }^{1}$

\begin{tabular}{|c|c|c|c|c|c|c|c|c|c|c|c|c|c|c|}
\hline \multirow[t]{2}{*}{ Effect } & \multicolumn{2}{|c|}{ a-glucosidase } & \multicolumn{2}{|c|}{$\beta$-glucosidase } & \multicolumn{2}{|c|}{ a-galactosidase } & \multicolumn{2}{|c|}{$\beta$-galactosidase } & \multicolumn{2}{|c|}{$\beta$-glucuronidase } & \multicolumn{2}{|c|}{$\begin{array}{l}\text { a-arabino- } \\
\text { pyranosidase }\end{array}$} & \multicolumn{2}{|c|}{$\beta$-xylosidase } \\
\hline & extra $^{2}$ & intra $^{3}$ & extra $^{2}$ & intra $^{3}$ & extra $^{2}$ & intra $^{3}$ & extra $^{2}$ & intra $^{3}$ & extra $^{2}$ & intra $^{3}$ & extra ${ }^{2}$ & intra $^{3}$ & extra $^{2}$ & intra $^{3}$ \\
\hline \multicolumn{15}{|l|}{ Treatment $^{4}$} \\
\hline A & 50.4 & 8.41 & 25.0 & 12.1 & 42.5 & 49.1 & 52.0 & 47.2 & 41.3 & 28.8 & 3.29 & 3.48 & 12.3 & 13.8 \\
\hline$A_{w w}$ & 65.1 & 11.5 & 22.4 & 13.2 & 45.7 & 41.1 & 64.1 & 41.9 & 52.0 & 24.5 & 3.61 & 3.51 & 14.6 & 12.8 \\
\hline$B^{w w}$ & 40.5 & 7.86 & 19.9 & 12.1 & 46.6 & 42.3 & 54.2 & 47.5 & 40.0 & 34.2 & 1.76 & 3.66 & 11.0 & 13.4 \\
\hline $\mathrm{B}_{w w}$ & 66.1 & 11.6 & 24.6 & 13.1 & 49.6 & 41.1 & 65.6 & 38.9 & 46.6 & 40.8 & 3.23 & 3.98 & 12.6 & 14.2 \\
\hline Pooled SEM & 3.241 & 0.902 & 1.664 & 0.796 & 2.563 & 2.755 & 5.338 & 5.131 & 3.349 & 2.591 & 0.295 & 0.314 & 0.961 & 0.825 \\
\hline \multicolumn{15}{|c|}{ Whole wheat } \\
\hline$W_{0}$ & $45.4^{\mathrm{B}}$ & 8.14 & 22.4 & 12.1 & 44.5 & 45.7 & 53.1 & 47.4 & 40.6 & 31.5 & 2.52 & 3.57 & 11.6 & 13.6 \\
\hline$W_{200}$ & $65.6^{\mathrm{A}}$ & 11.6 & 23.5 & 13.1 & 47.6 & 41.1 & 64.9 & 40.4 & 49.3 & 32.6 & 3.42 & 3.74 & 13.6 & 13.5 \\
\hline \multicolumn{15}{|c|}{ Diet } \\
\hline $\mathrm{A}(\mathrm{NRC})$ & 53.3 & 9.72 & 22.3 & 12.6 & 48.1 & 41.7 & 59.9 & 43.2 & 43.3 & $37.5^{\mathrm{a}}$ & 2.49 & 3.82 & 11.8 & 13.8 \\
\hline $\mathrm{B}(\mathrm{BUT})$ & 57.7 & 9.97 & 23.7 & 12.6 & 44.1 & 45.1 & 58.1 & 44.6 & 46.6 & $36.4^{\mathrm{b}}$ & 3.45 & 3.50 & 13.4 & 13.3 \\
\hline
\end{tabular}

${ }^{1}$ data represent mean values of 6 replications per treatment. SEM - standard error of the mean (SD divided by the square root of the number of replications, $n=24) ;{ }^{2}$ extracellular activity, $\mu \mathrm{mol} \cdot \mathrm{h} \cdot \mathrm{g}^{-1} ;{ }^{3}$ intracellular activity, $\mu \mathrm{mol} \cdot \mathrm{h} \cdot \mathrm{g}^{-1} ;{ }^{4}$ diets $\mathrm{A}$ and $\mathrm{B}$ consistent with the NRC (1994) and B.U.T. (2012) recommendations, respectively. In the diets $A_{w w}$ and $B_{w w} 200 \mathrm{~g}$ ground wheat was substituted by whole wheat; $a, b, A, B$ means with different superscripts within columns for each main effect are significantly different at $P<0.05$ and $P<0.01$, respectively. All interactions insignificant

Table 6. Short chain fatty acid (SCFA) concentrations ( $\mu \mathrm{mol} \cdot \mathrm{g}^{-1}$ digesta) and SCFA profile (\% of total SCFAs) in the caecal digesta of turkeys ${ }^{1}$

\begin{tabular}{|c|c|c|c|c|c|c|c|c|c|c|}
\hline \multirow{2}{*}{ Effect } & \multicolumn{7}{|c|}{ SCFA concentrations, $\mu \mathrm{mol} \cdot \mathrm{g}^{-1}$ fresh digesta } & \multicolumn{3}{|c|}{ Profile, $\%$ of total SCFAs } \\
\hline & $\mathrm{C} 2$ & C3 & $\mathrm{C} 4 \mathrm{i}$ & $\mathrm{C} 4$ & $\mathrm{C} 5 \mathrm{i}$ & $\mathrm{C} 5$ & Total & $\mathrm{C} 2$ & C3 & C4 \\
\hline \multicolumn{11}{|l|}{ Treatment $^{2}$} \\
\hline A & 101 & 32.0 & 2.87 & 25.1 & 3.95 & 4.47 & 170 & 59.7 & 18.9 & 14.8 \\
\hline$A_{w w}$ & 125 & 45.6 & 1.6 & 40.1 & 3.21 & 3.98 & 218 & 57.2 & 21.1 & 18.3 \\
\hline$B$ & 84.2 & 28.2 & 2.08 & 21.9 & 3.29 & 4.63 & 144 & 58.3 & 19.5 & 15.2 \\
\hline$B_{w w}$ & 123 & 45.9 & 1.61 & 43.1 & 3.60 & 4.31 & 222 & 56.0 & 20.6 & 19.1 \\
\hline SEM ${ }^{\text {wW }}$ & 4.439 & 2.042 & 0.214 & 2.474 & 0.264 & 0.265 & 8.330 & 0.639 & 0.437 & 0.635 \\
\hline \multicolumn{11}{|l|}{ Whole wheat } \\
\hline$W_{0}$ & $92.8^{\mathrm{B}}$ & $30.1^{\mathrm{B}}$ & $2.47^{\mathrm{A}}$ & $23.5^{\mathrm{B}}$ & 3.62 & 4.55 & $157^{\mathrm{B}}$ & 59.0 & 19.2 & $15.0^{\mathrm{B}}$ \\
\hline$W_{200}$ & $124^{\mathrm{A}}$ & $45.8^{\mathrm{A}}$ & $1.34^{\mathrm{B}}$ & $41.6^{A}$ & 2.95 & 4.15 & $220^{A}$ & 56.6 & 20.8 & $18.7^{\mathrm{A}}$ \\
\hline \multicolumn{11}{|l|}{ Diet } \\
\hline $\mathrm{A}(\mathrm{NRC})$ & 104 & 37.0 & 1.85 & 32.5 & 3.44 & 4.47 & 183 & 57.2 & 20.1 & 17.1 \\
\hline $\mathrm{B}$ (BUT) & 113 & 38.8 & 1.97 & 32.6 & 3.13 & 4.23 & 194 & 58.5 & 20.0 & 16.5 \\
\hline
\end{tabular}

${ }_{1}^{1}$ data represent mean values of 6 replications per treatment. SEM - standard error of the mean (SD divided by the square root of the number of replications, $n=24) ; 2$ diets A and B consistent with the NRC (1994) and B.U.T. (2012) recommendations, respectively. In the diets $A_{w w}$ and $B_{w w}$ $200 \mathrm{~g}$ ground wheat was substituted by whole wheat; ${ }^{A, B}$ means with different superscripts within columns for each main effect are significantly different at $P<0.01$. All interactions insignificant 
Table 7. Main effects of dietary treatments on excreta DM content and FPD symptoms at 18 weeks of age ${ }^{1}$ and mortality of turkeys ${ }^{1}$

\begin{tabular}{|c|c|c|c|}
\hline Effect & $\mathrm{DM}, \%$ & FPD, points & $\begin{array}{l}\text { Mortality, } \% \\
1-18 \text { wk }\end{array}$ \\
\hline \multicolumn{4}{|l|}{ Whole wheat } \\
\hline$W_{0}$ & 21.6 & 1.42 & 3.86 \\
\hline$W_{200}$ & 21.0 & 1.58 & 3.13 \\
\hline \multicolumn{4}{|l|}{ Diet } \\
\hline $\mathrm{A}(\mathrm{NRC})$ & 21.3 & 1.58 & 3.85 \\
\hline $\mathrm{B}(\mathrm{BUT})$ & 21.2 & 1.44 & 3.14 \\
\hline Pooled SEM & 0.217 & 0.078 & - \\
\hline
\end{tabular}

${ }^{1}$ data represent mean values of 7 replications per treatment; SEM standard error of the mean (SD divided by the square root of the number of replications, $n=28$ ). All differences and interactions insignificant

rameters of intestinal development and function, significant differences were noted only with respect to the $\mathrm{pH}$ of caecal digesta (Table 4), which was lower $(P=0.001)$ in turkeys fed $20 \% \mathrm{WW}$.

Differences in diet composition, including WW content, had a minor effect on microbial enzyme activity in the caecum (Table 5). The $20 \% \mathrm{WW}$ inclusion rate contributed to a significant increase in the activity levels of extracellular and intracellular $\alpha$-glucosidase, determined in the native caecal digesta $(P=0.001)$ and in the caecal digesta that was homogenized to release enzymes from bacterial cells $(P=0.068)$, respectively. No differences were observed in the activities of the other analysed enzymes in the caecal microflora.

The caecal digesta of turkeys fed $20 \% \mathrm{WW}$ was characterized by significantly higher concentrations of acetate, propionate, butyrate and total SCFAs (all $P=0.001)$, and lower $(P=0.004)$ isobutyrate levels (Table 6). The proportion of acetate decreased $(P=0.062)$ and the percentages of propionate and butyrate $(P=0.006$ and $P=0.002$, respectively) increased in the total SCFA pool determined in the caecal digesta of turkeys fed $20 \%$ WW. No significant differences were found in SCFA concentrations in the caecal digesta of turkeys fed $\operatorname{diets}$ A and B.

The applied dietary treatments had no effect on excreta DM, FPD scores at the end of the experiment, or mortality rates of birds over the entire experiment (Table 7).

\section{Discussion}

Numerous experiments performed on chickens have shown that whole grains stimulate development of the gastrointestinal tract (including an increase in the weights of the proventiculus and gizzard), thus improving feed efficiency and/or increasing BWG (Bennet at al., 2002; Gabriel et al., 2008; Biggs and Parsons, 2009; Svihus et al., 2010).
Studies investigating the effect of whole grains in turkeys remain scarce, and their results are inconclusive. Bennett et al. (2002) demonstrated that the BWG of turkey was unaffected by feeding increasing levels of whole barley $(5 \%, 20 \%$ and $50 \%$ on days 19-33, 34-40 and 41-96) when the diets were supplemented with a protein-mineral-vitamin concentrate. In our earlier study (Jankowski et al., 2013), when the diets were supplemented with a protein-mineral concentrate, a substantial decrease in body weight was noted at a higher (about $40 \%$ ) inclusion rate of WW. In the present study, WW added to pelleted diets at $20 \%$ had no influence on the BWG or final body weights of turkeys, which corroborates the above findings.

The results of previous studies on turkeys do not explain the effect of the content of whole grain in the diet on feed conversion. Bennett et al. (2002) noted similar FCR values for diets containing whole and ground barley, whereas Bennett and Classen (2003) reported a worse FCR in turkeys fed a commercial diet diluted with wheat grain. In our earlier study (Jankowski et al., 2013), a low substitution level of ground wheat by whole wheat $(12.5 \%$ and $15 \%$ whole grain wheat content of the daily ration in weeks $4-8$ and $9-12$, respectively) did not negatively affect the feed conversion ratio, but two-fold higher whole grain inclusion levels deteriorated FCR. At the first stage of the present experiment (weeks 5-8), the applied dietary treatments had no effect on FCR. In the second and third phase (weeks 9-12 and 13-18), dietary inclusion of WW at 20\% progressively deteriorated FCR $(P=0.064$ and 0.040 , respectively), compared with ground wheat. Our findings indicate that the negative effect of WW on feed efficiency was not determined by the bird's age but by increased consumption of feed containing WW.

In the current study, the proportions of major muscle groups (including breast muscles) in turkey carcasses were not affected by the physical form of wheat. The experimental factor had no effect on the final body weights of birds, either. In an experiment by Bennett and Classen (2003), a high level of diet dilution with wheat (from $21 \%$ to $29 \%$ ) significantly reduced the final body weights of turkeys and the weight of breast meat per bird, by $15 \%$ and $20 \%$, respectively. We did not note a decrease in carcass fat content in response to feeding wheat-diluted diets, which was reported in an experiment involving broiler chickens (Amerah and Ravindran, 2008).

No increase in the weight of the gizzard or small intestine was observed in our study. According to many authors (Bennett et al., 2002; Amerah and 
Ravindran, 2008; Biggs and Parsons, 2009; Jankowski et al., 2013; Zdunczyk et al., 2013), relative gizzard weight can be increased by feeding whole grains to chickens and turkeys. An increase in gizzard size was reported by $\mathrm{Wu}$ et al. (2004) at post-pelleting inclusion of $20 \% \mathrm{WW}$, whereas no such effect was observed at pre-pelleting inclusion of WW. The findings of Wu et al. (2004) and our results may suggest that the pelletizing process changes the physicochemical properties of cereal grain and accelerates the passage rate of pelleted feed, compared with whole grain fed with a pelleted diet.

Previous experiments (Biggs and Parsons, 2009) have demonstrated that the wheat content of chicken diets had no effect on SCFA concentrations in the caecal digesta. According to Gabriel et al. (2008), wheat grain improves gizzard function and nutrient digestibility, thus reducing the amount of substrate available for the proliferation of intestinal microbiota. Different results were obtained in a previous experiment on turkeys where wheat grain increased SCFA concentrations in the caecal digesta and the weight of the caecal wall (Zdunczyk et al., 2013). In the current study, the inclusion of WW in turkey diets enhanced the activity of microbial $\alpha$-glucosidase. The increase in the glycolytic activity of gut microflora was followed by an increase in the SCFA concentrations and a decrease in $\mathrm{pH}$. The above suggest that pre-pelleting inclusion of wheat increases the amounts of carbohydrates in the caecal digesta, which are degraded to SCFAs. However, the energy provided by carbohydrates fermented in the caecum contributes approximately $3.5 \%$ of metabolizable energy in poultry (Jamroz et al., 2002). This explains reduced utilization of WW-based diets, despite a significant increase in the production of SCFAs in the caecum.

In our previous studies (Jankowski et al., 2012a, 2013; Zdunczyk et al., 2013), the severity of FPD varied among young turkeys, but at the end of fattening (at the highest level of diet dilution with wheat) no significant differences were found between groups in this respect. In the present study, the experimental factors had no significant effect on excreta DM. It is known that high excreta moisture increases the risk of FPD in poultry (Jankowski et al., 2012b).

Different feeding regimes had an insignificant effect on the parameters of gastrointestinal function, including SCFA concentrations in the caecal digesta. Changes in the carbohydrate composition of diets, caused by different inclusion levels of soyabean meal and wheat, were small, particularly in the first phase of feeding. In our previous studies (Jankowski et al., 2009), enhanced caecal fermenta- tion in young turkeys could have resulted from high concentrations of raffinose family oligosaccharides rather than from the crude fibre content of diets (Zdunczyk et al., 2010).

In this study, feed efficiency was higher in turkeys fed diet B formulated as recommended by B.U.T. (2012). The above could be due to the fact that from 9 weeks of age the content of amino acids and total protein was reduced to a lesser extent in diet $\mathrm{B}$ than in $\operatorname{diet} \mathrm{A}$ formulated as recommended by the NRC (1994). As a result, nutrient density per unit of metabolizable energy was higher in diet B. In the last phase of feeding, the wheat-to-soyabean meal ratio in diets A and B reached 7:1 and 4:1, respectively. It seems that nutrients provided by soyabean meal are more efficiently utilized than those supplied by wheat. Other authors (Waldroup et al., 1997; Applegate et al., 2008) demonstrated that the amino acid levels suggested by NRC (1994) were adequate to support maximum performance in turkeys. In a study by Applegate et al. (2008), diets formulated with supplemental amino acids to $100 \%$ or $110 \%$ of NRC (1994) amino acid recommendations had no effect on the body weights of turkeys and breast meat yield.

\section{Conclusions}

The results of our study indicate that in both feeding programmes, $20 \%$ inclusion of whle wheat (WW) in pelleted diets may deteriorate the feed conversion ratio (FCR), without significantly decreasing the body weight gain of turkeys. Increased production of short-chain fatty acids in the caeca of turkeys fed WW did not compensate the deterioration in FCR. Compared with the diet based on NRC (1994) recommendations, the diet consistent with the B.U.T. (2012) recommendations significantly improved the FCR in turkeys.

\section{Acknowledgements}

This work was supported by the Polish National Science Center, Project No. NN311 400339.

\section{References}

Amerah A.M., Peron A., Zaefarian F., Ravindran V., 2011. Influence of whole wheat inclusion and a blend of essential oils on the performance, nutrient utilization, digestive tract development and ileal microbiota profile of broiler chickens. Brit. Poultry Sci. 52, 124-132

Amerah A.M., Ravindran V., 2008. Influence of method of whole-wheat feeding on the performance, digestive tract development and carcass traits of broiler chickens. Anim. Feed Sci. Tech. 147, 326-339 
Applegate T.J., Powers W.J., Ange I R., Hoehler D., 2008. Effect of amino acid formulation and acid supplementation on performance and nitrogen excretion in turkey toms. Poultry Sci. $87,514-520$

Bennett C.D., Classen H.L., 2003. Effect of whole wheat dilution on performance and carcass characteristics of male turkey. J. Appl. Poultry Res. 12, 468-475

Bennett C.D., Classen H.L., Schwean K., Riddell C., 2002. Influence of whole barley and grit on live performance and health of turkey toms. Poultry Sci. 81, 1850-1855

Biggs P., Parsons C.M., 2009. The effect of whole grains on nutrient digestibilities, growth performance, and cecal short-chain fatty acid concentrations in young chicks fed ground cornsoybean meal diets. Poultry Sci. 88, 1893-1905

Blair M.E., Potter L.M., Hulet R.M., 1989. Effects of dietary protein and added fat on turkeys varying in strain, sex, and age. 2. Carcass characteristics. Poultry Sci. 68, 287-296

B.U.T., 2012. Commercial Performance Goals. British United Turkeys Ltd. $5^{\text {th }}$ Edition. Warren Hall, Broughton, Chester (UK). Accessed November 22, 2009. http://www.aviagen.com/ home. aspx?siteld=8

Ferket P.R., Sell J.L., 1990. Effect of early protein and energy restriction of Large turkey toms fed high-fat or low-fat realimentation diets. 2. Carcass characteristics. Poultry Sci. 69, 1982-1990

Hofirek B., Haas D., 2001. Comparative studies of ruminal fluid collected by oral tube or by puncture of the caudorental ruminal sac. Acta Vet. Brno 70, 27-33

Gabriel I., Mallet S., Leconte M., Travel A., Lalles J.P., 2008. Effect of whole wheat feeding on the digestive tract of broiler chickens. Anim. Feed Sci. Tech. 142, 144-162

Jamroz D., Jakobsen K., Knudsen K.E.B., Wiliczkiewicz A., Orda J., 2002. Digestibility and energy value of non-starch polysaccharides in young chickens, ducks and geese, fed diets containing high amounts of barley. Comp. Biochem. Physiol. Pt A 131, 657-668

Jankowski J., Juśkiewicz J., Gulewicz K., Lecewicz A., Slominski B.A., Zduńczyk Z., 2009. The effect of diets containing soybean meal, soybean protein concentrate and soybean protein isolate of different oligosaccharide content on growth performance and gut function of young turkeys. Poultry Sci. 88, 2132-2140

Jankowski J., Mikulski D., Zduńczyk Z., Mikulska M., Juśkiewicz J., 2012a. The effect of diluting diets with ground and pelleted or with whole wheat on the on the performance of growing turkeys. J. Anim. Feed Sci. 21, 735-747
Jankowski J., Zduńczyk Z., Lichtorowicz K., Juśkiewicz J., 2012b. Effect of different levels of dietary sodium from sodium chloride on gastrointestinal tract response, tibia mineralization, and footpad dermatitis incidence in young turkeys. J. Appl. Poultry Res. 21, 856-867

Jankowski J., Zduńczyk Z., Mikulski D., Przybylska-Gornowicz B., Sosnowska E., Juśkiewicz J., 2013. Effect of whole wheat feeding on gastrointestinal tract development and performance of growing turkeys. Anim. Feed Sci. Tech. 185, 150-159

Juskiewicz J. Gruzauskas R., Zdunczyk Z., Semaskaite A., Jankowski J., Totilas Z., Jarule V., Sayte V., Zdunczyk P., 2011. Effect of dietary addition of Marleya cordata alkaloid on growth performance, caecal indices and breast meat fatty acid profile in male broiler. J. Anim. Physiol. Anim. Nutr. 95, 171-178

Krautwald-Junghanns M.E, Ellerich R., Mitterer-Istyagin H., Ludewig M., Fehlhaber K., Schuster E., Berk J., Petermann S., Bartels T., 2011. Examinations on the prevalence of footpad lesions and breast skin lesions in British United Turkeys Big 6 fattening turkeys in Germany. Part I: Prevalence of footpad lesions. Poultry Sci. 90, 555-560

NRC, 1994. Nutrient Requirements of Poultry. $9^{\text {th }}$ revised Edition. National Academic Press. Washington, DC

Smulikowska S., Rutkowski A. (Editors), 2005. Recommended Allowances and Nutritive Value of Feedstuffs - Poultry Feeding Standards (in Polish). $4^{\text {th }}$ Edition. The Kielanowski Institute of Animal Physiology and Nutrition, PAS, Jabłonna (Poland), pp. 117-119

Snedecor G.W., Cochran W.G., 1989. Statistical Methods. $8^{\text {th }}$ Edition. Ames (IA), lowa State University Press

Svihus B., Sacranie A., Denstadli V., Choct M., 2010. Nutrient utilization and functionality of the anterior digestive tract caused by intermittent feeding and inclusion of whole wheat in diets for broiler chickens. Poultry Sci. 89, 26172625

Waldroup P.W., Adams P.W., Waldroup A.L., 1997. Evaluation of National Research Council amino acid recommendations for large white turkeys. Poultry Sci. 76, 711-720

Wu Y.B., Ravindran V., Thomas D.G., Birtles M.J., Hendriks W.H., 2004. Influence of method of whole wheat inclusion and xylanase supplementation on the performance, apparent metabolizable energy, digestive tract measurements, and gut morphology of broilers. Brit. Poultry Sci. 45, 385-394 